\title{
Can prebiotic systems survive in the wild? An interference chemistry approach
}

\author{
Craig Walton ${ }^{1}$, Paul Rimmer ${ }^{1,2}$, and Oliver Shorttle ${ }^{1,3}$ \\ ${ }^{1}$ Department of Earth Sciences, University of Cambridge, Downing Street, Cambridge CB2 3EQ, UK \\ ${ }^{2}$ Cavendish Astrophysics, University of Cambridge, JJ Thomson Avenue, Cambridge CB3 OHE, UK \\ 3 Institute of Astronomy, University of Cambridge, Madingley Road, Cambridge, CB3 OHA UK
}

\begin{abstract}
The origin of life occurred by a series of prebiotic reaction pathways (collectively a system) hosted in one or more geochemical environments (together forming an origin of life scenario). State-of-the-art prebiotic chemistry links together reactions to create systems, intended to be more representative of the diverse chemical pathways that may have proceeded on early Earth. By practical necessity, prebiotic systems chemistry must be investigated under simplified conditions in comparison to likely natural environments. The mismatch in complexity between lab and environment poses a challenge: how to build systems chemistry that is robust not only in the idealised conditions of a lab, but also under natural levels of environmental stress? Here, we propose and formalise a conceptual framework for such work: interference chemistry. We define interference chemistry as the interaction between prebiotic systems chemistry and the environmental scenarios proposed to host it. Natural environments in which prebiotic chemistry could have occurred are messy, containing many spectator ions, mineral phases, and spatially and temporally variable physical processes, e.g., wet/dry cycles. Each of these environmental variables may interfere either constructively or destructively with prebiotic pathways, respectively aiding or inhibiting their efficacy. Exploring interference chemistry for a reaction system will point towards favoured or disfavoured regions of environmental parameter space. To do so, innovation is needed in both the investigation of early planetary environmental conditions, and the continued incorporation of these constraints into experimental systems chemistry. We argue that interference chemistry provides a compelling way to assess combinations of system and environment, leading the way to increasingly prebiotically plausible scenarios for the origin of life on Earth.
\end{abstract}

\section{Prebiotic chemistry: a parameter space problem}

The origin of life occurred by a series of prebiotic reaction pathways (collectively a system) hosted in one or more geochemical environments (together forming an origin of life scenario). Potentially prebiotic reaction pathways have now been published for membranes, information-storing polymers, and compounds that appear universally in extant metabolism [1-17]. New constraints on early Earth geochemistry offer constraints on possible environmental settings for the origin of life (see Section 3, Table 1). Despite this progress, substantial challenges remain with linking these promising chemical pathways into a coherent and prebiotically plausible scenario for the origin of life.

Successful syntheses demand a high level of chemical selectivity. In the quest to achieve such syntheses, reactions are necessarily run under controlled conditions that are generally absent in naturally occurring environmental scenarios. The unavoidable complexity of geochemical environments is challenging to incorporate into experimental reaction schemes. It remains to be fully demonstrated whether and how such prebiotic syntheses would proceed in environments with increased geochemical complexity, or indeed what constraints prebiotic chemistry can place on the wider environmental chemistry of terrestrial-type planets. These long-noted challenges $[18,19]$ are compounded by an ongoing proliferation in the number of proposed origin systems and scenarios, which create a continually expanding physical-chemical parameter space in which the efficacy of prebiotic pathways should be tested. (Figure 1). As a consequence of these problems, the question of how to measure progress in prebiotic chemistry remains unclear [7,20-23]. 
The unique challenge of prebiotic chemistry can be summarized by noting that no individual experiment or environment is itself necessarily related to the origin of life. As a consequence, any given synthesis is always an exploration of fundamental chemical parameter space, but not necessarily the prebiotic parameter space that gave rise to extant life. However, the intractably large scope of the experimental and prebiotic parameter spaces can in principle be bounded by some basic assumptions:

Assumption 1: origin of life took place on Earth.

Assumption 2: the broad molecular architecture of modern life is essentially conserved from the prebiotic Earth.

Assumption 3: central chemical reactions that universally characterize extant biology were proto-typed in the Prebiotic Era, e.g., at a minimum, RNA polymerisation, phosphate-based metabolism, and amphiphile-based compartmentalisation.

Carrying assumptions 1-3 forward, a plausible model for the origin of life should identify the overlap between plausible environmental parameter space on the early Earth and favourable conditions for linked prebiotic reactions that were relevant, either directly or as an intermediate step, for the emergence of extant biochemistry. Difficulties in this approach centrally arise from:

Challenge 1: identifying reactions that could have formed a bridge from prebiotic chemistry to the first life.

Challenge 2: uncertainty in the environmental conditions prevailing on prebiotic Earth.

Challenge 3: a lack of preserved rock record from the prebiotic Era.

Owing to these challenges, the environmental context of plausibly prebiotic chemistry remains highly uncertain. This point complicates a critical issue: that 'prebiotic plausibility' is a poorly defined term without constraints on the prebiotic systems and environments relevant to early Earth. Despite thoughtful discussion over many years in the literature [19,23], a consensus on how to define prebiotic plausibility in a self-consistent manner has yet to be reached. Such a framework for prebiotic plausibility would allow for comparison of system and environment combinations, thus providing a measure by which to assess progress in the field at large.

The need to tackle these issues has recently given rise to the concept of prebiotic systems chemistry: the idea of performing multiple reactions in sequence, as part of a prebiotic chemical network, with some of the same reactants and spectators present throughout [7,24-26]. Systems chemistry posits that increasingly complex experiments, wherein multiple steps are explicitly and successfully linked, are more analogous to the prebiotic chemistry that must have taken place in naturally occurring environments. From this perspective, systems chemistry experiments inherently have more explanatory power than single reaction pathways, with the potential to produce more plausible reaction pathways, networks, and, ultimately, scenarios for the origin of life. However, prebiotic systems chemistry must also explore a vast and multifaceted chemical parameter space.

Here, we propose the concept of interference chemistry: a subset of systems chemistry, intended to identify the connections and feedbacks between prebiotic chemical systems and geochemical environments. In turn, common themes discovered in the chemistry can inform which geochemical scenarios are most likely. We explore how interference chemistry may aid with identifying regions of prebiotically plausible parameter space for specific scenarios. 


\section{Systems versus interference chemistry}

Systems chemistry broadly relies on matching a set of reactions that occur in the lab to plausible conducive settings on the early Earth (Figure 2). This approach often lacks systematic information regarding the broader environmental dependencies of the reaction pathway, e.g., P, T, solution chemistry, and so on. It is therefore often challenging to identify the compatible geological environments for different experimental reaction schemes. That being said, the relative simplicity of the single reaction and systems approaches have so far constituted the only reasonable paths for prebiotic chemistry to pursue. This is so because a full parameter space sweep is impractical given a purely experimental approach.

Including the complete inorganic and organic complexity inherent to a naturally occurring prebiotic environment is neither (1) conducive to understanding the chemistry being explored in any given experiment, nor (2) helpful until the nature of the competing reactions and interfering inorganic/organic species are understood [27,28]. It is only now, with an emerging understanding of fundamental and potentially plausible prebiotic chemistry, that we can begin to consider an increasingly multi-faceted approach. Here, we propose one such approach: interference chemistry.

We define interference chemistry as the interaction between an environmental scenario and prebiotic system (Figure 2). The environmental scenario encompasses the pressure and temperature conditions at which reactions take place, and also the environmental context in terms of atmospheric, aqueous and substrate composition, environmental geometry, fluid dynamics, timescales, etc. Natural environments in which prebiotic chemistry could have occurred are messy, containing many spectator ions, mineral phases, and spatially and temporally variable physical processes, e.g., wet/dry cycles. Each of these environmental variables may interfere with prebiotic pathways. This interference may be constructive, e.g., the warming of the environment to melt ice and allow aqueous reactions to occur; it may be destructive, e.g., the continued heating of the environment and eventual thermal degradation of organic products; or it may be neutral, having no effect on the pathway at hand.

The ultimate goal of interference chemistry is to understand the resilience of prebiotic reaction systems under environmental stress. Many insights have already been gleaned by experiments that include a greater number of plausible prebiotic interferences, e.g., the unexpectedly advantageous inclusion of phosphate in HCN-centric systems chemistry [29], and indeed from the flow of information between prebiotic chemistry and early Earth geochemistry. Interference chemistry provides a framework for the systematising of constraints on both constructive and destructive interferences in prebiotic chemistry.

Combining the logic of systems and interference chemistry approaches, we propose a new over-arching definition of prebiotic plausibility:

A prebiotically plausible scenario for the origin of life is one in which the proposed prebiotic system is 1) efficacious in the laboratory setting, 2) utilises only reactants and processes that likely co-occurred in geological environments, and 3) that remains efficacious given the local conditions of an environment, or suite of connected environments.

We suggest that iterative testing of this kind, between the laboratory and putative environmental settings for the origin of life, can identify the overlap between successful experimental conditions and reconstructions of ancient planetary environments, i.e., prebiotically plausible parameter space [26]. However, this type of research is limited not only by experimental practicality, but also by our knowledge of which specific interferences are associated with prebiotic environments, uncertainty in which makes it difficult to bridge lab and environment (Figure 2).

Often, in order to ensure rigorous understanding of a reaction or system of reactions, only those species and variables that are sufficient to synthesise the desired products are included in a experiment. As such, these approaches may be highly sensitive to developments in our understanding of early Earth, whereby new constraints on the availability/occurrence of specific species/processes can dramatically alter the apparent plausibility of pathway. From the perspective of planetary science, it is also often much easier to 
(1) say what interferences were not present than to establish those which were, and to (2) establish limited global constraints on environmental conditions, rather than to specify the detailed local environmental conditions needed to constrain origin of life scenarios. Interference chemistry points towards a more systematic exploration of prebiotic pathways and the scenarios that may have hosted them. In this context, prebiotic systems are subjected to the full environmental stresses associated with proposed scenarios.

By understanding the effect of individual and interacting interferences more broadly, we hypothesize that it will become possible to identify more or less favoured origin of life scenarios iteratively, as progress is made by both prebiotic chemists, on the feasibility of reaction systems, and earth scientists, on the nature of prebiotic environments. The interference chemistry framework has at its core an efficient two-way flow of information between prebiotic chemistry and the study of early Earth conditions: whereby the reactions that drove the origin of life (as well as those that did not, but still widely occurred) will have acted to shape both local environments and ultimately global planetary conditions. At the same time, prevailing environmental conditions will have determined the plausibility and feasibility of particular origin of life scenarios. Interference chemistry may therefore be leveraged in pursuit of dual constraints on (1) wider environmental conditions at the dawn of life and (2) the specific environments in which life may have emerged.

Even environmental parameter space that is not plausible for early Earth may well apply to other worlds of prebiotic interest. Integrating planetary and environmental geochemistry with prebiotic chemistry is therefore relevant for mapping out the efficacy of origin of life scenarios on the cosmic scale. However, at least for now, constraints on early Earth global and local environments are the most fully developed among worlds of prebiotic interest, e.g., Mars. In the next section, we present a compilation of constraints on the compositions and conditions of early Earth environments and their associated interferences.

\section{Environmental parameter space of prebiotic Earth}

Much is uncertain about the nature of prebiotic Earth. The timeline, surface conditions, and basic geology of the planet in this state are all difficult to ascertain, owing to a lack of a rock record for the first half billion years of Earth history (4.45-4.0 Ga - early Earth, from here-on-in). Via a combination of extrapolation and theoretical study, there is consensus that early Earth atmosphere was anoxic, with somewhat clement surface temperatures, and that there were surface oceans rich in dissolved iron [3040]. Much more uncertain is the extent of emergent land (of any rock type), the composition and mere existence of continents, whether or not the atmosphere was highly reducing, and if those generically habitable surface conditions leaned towards global icehouse or hothouse conditions [36,37,40-51].

In Table 1, we summarise the geochemical characteristics of a number of commonly invoked prebiotic environmental scenarios for early Earth. Our compendium provides an overview of environmental parameters that can be used as a starting point for interference chemistry research, e.g., by the exposure of two proposed prebiotic systems to same set of environmental interferences. By considering which system is more robust to the interferences thought to be present in naturally occurring environments on early Earth, information will be gleaned on which system-environment combination is most plausible as a scenario for the origin of life.

We rely on modern analogues that have been studied in detail as the basis of our compendium, supplemented where possible with what is known about each specific environmental interference on early Earth. Some species found in in key environments for prebiotic chemistry are highly sensitive to surface conditions, yet have not received detailed modelling or experimental studies relevant to early Earth conditions. In Table 1, such especially uncertain estimates are shaded in orange. Conversely, estimates derived from studies designed to investigate prebiotic and/or early Earth (Archean) conditions are shaded in green.

As a key example of these uncertainties, we highlight alkaline lakes. Restricted subaerial environments are increasingly proposed in scenarios for the origin of life $[14,52,53]$. However, there are many open questions about the interference chemistry of such basins on early Earth. Sulphate concentrations in 
alkaline lakes are very high in the modern, approaching molal concentrations (Table 1). However, such systems are unlikely to have generated the same sulphate concentrations under an anoxic atmosphere and in the absence of sulphide-oxidising bacteria [54]. Similarly, dissolved iron concentrations are directly linked to oxidising power in the environment. With soluble ferrous iron $\left(\mathrm{Fe}^{2+}\right)$ being dominant in early Earth surface environments, it is likely that prebiotic analogues of modern surficial aqueous environments may have been fed by iron-rich inflow - although, iron carbonate mineral precipitation may have acted to limit final concentrations [52]. 


\section{Table 1: A geochemical roadmap of prebiotic Earth}

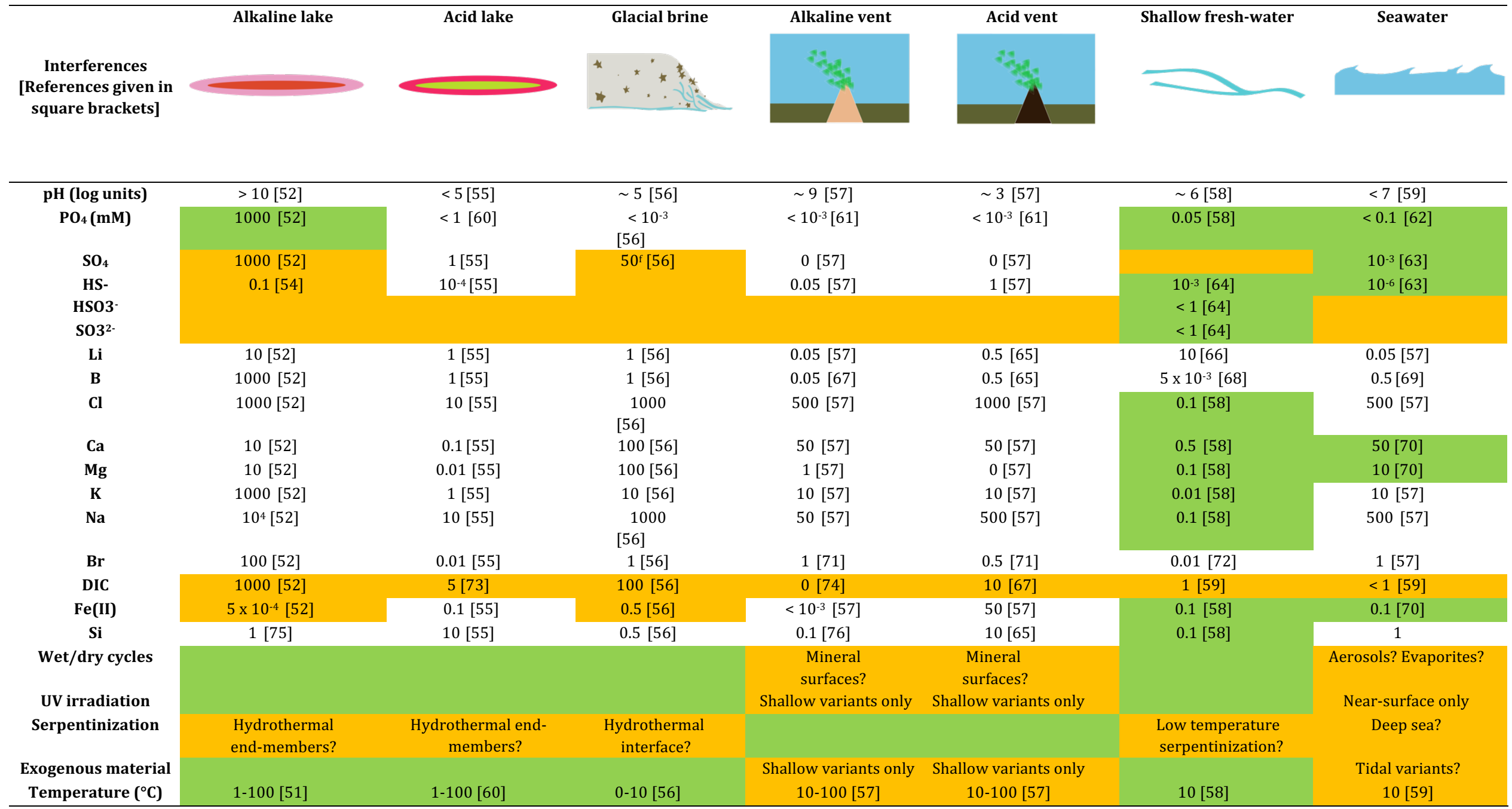

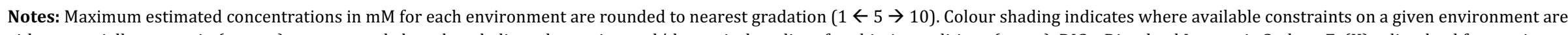

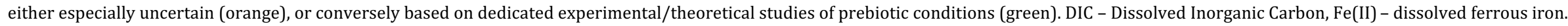
Additional references for acid and alkaline vent fluids in end-member compositions of Hodgkinson et al (2015) are as follows: [77-79]. This compilation is not intended to be exhaustive. 
Table 2: timescales of prebiotic chemistry and environmental processes

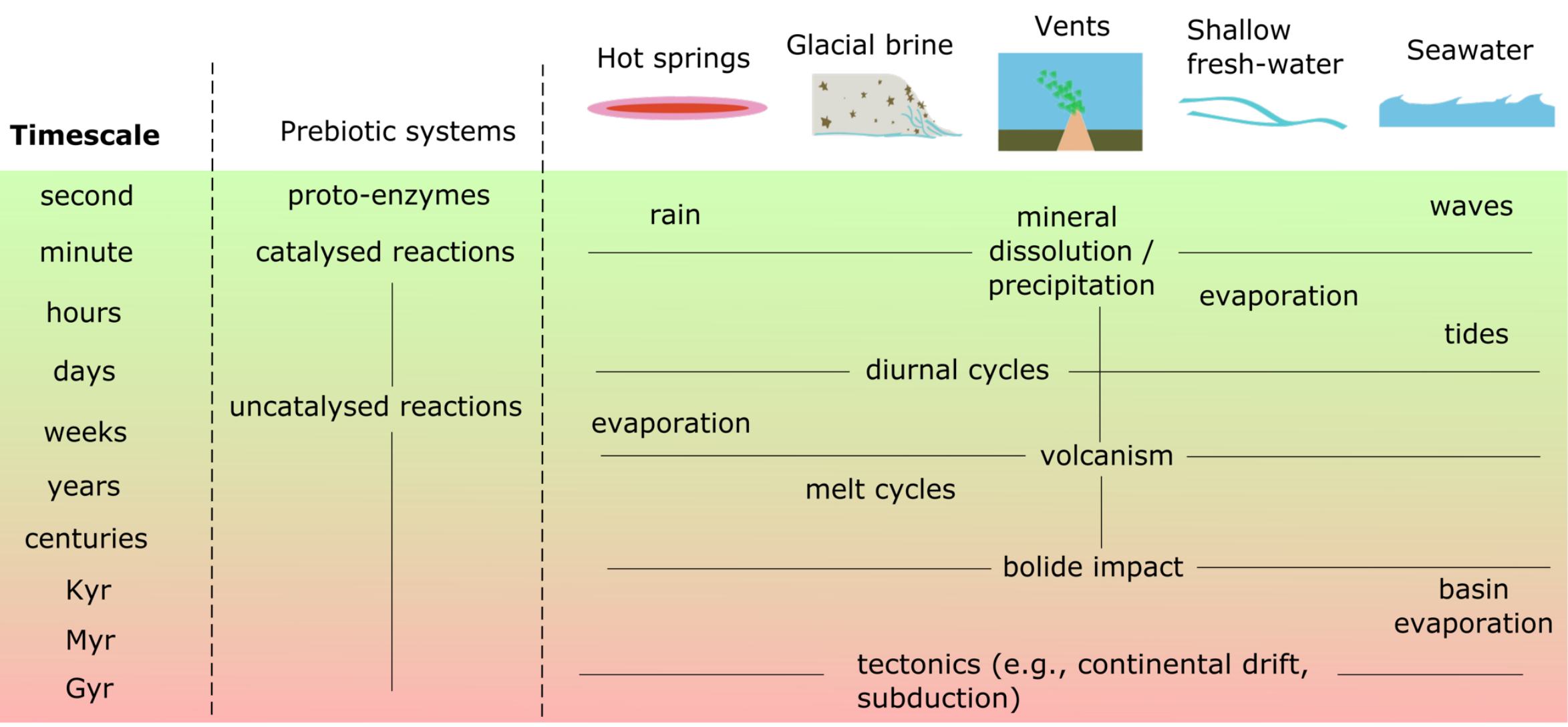


Finally, atmospheric $\mathrm{pCO}_{2}$ of early Earth is poorly constrained, rendering Dissolved Inorganic Carbon (DIC) estimates uncertain for all environments $[80,81]$. This uncertainty is especially problematic, as $\mathrm{pCO}_{2}$ and DIC are a major control on the $\mathrm{pH}$ and overall chemistry of restricted subaerial solutions in equilibrium with the atmosphere, e.g., phosphate content of soda lakes [52]. Available DIC is also required for abiotic production of organic carbon in many proposed prebiotic environments [67].

On the other hand, dedicated studies on ancient weathering processes and ocean chemistry more tightly constrain several key interferences in early river and ocean water (see Table 1). However, for most environments in Table 1, we do not highlight interferences as especially likely or unlikely to be reflective of plausibly prebiotic environments: for now, we simply do not know either way.

Our survey is far from all-encompassing. Mapping out environmental chemistry on Earth prior to the rise of life is a huge undertaking, and one which deserves greater attention in its own right, independent of the specific question of where life first began. The critical next step would be to understand more deeply the feedbacks between inorganic planetary chemistry and prebiotic organic chemistry, i.e., the defining features of prebiotic Earth. It is this broad base of knowledge that we argue to be critical to solving the origin of life - at least in part by its experimental and theoretical application in the form of interference chemistry. Just as life itself provides some of the best constraints on past terrestrial environments, the origins of life may provide the clearest insight into local environments on the prebiotic Earth.

\section{Implementing interference chemistry}

Implementing interference chemistry in a laboratory context requires overcoming two main challenges: 1) that mapping destructive interferences necessarily means running experiments that 'fail' in the sense of producing high yields of a desired product - this is a challenge to a culture where we may prefer to run and report on successful experiments; and, 2) the large volume of environmental parameter space, both physical and chemical (Table 1 and 2), that exploration of interference chemistry represents. It is therefore useful for us to overview the feasibility of interference chemistry by considering previous similar approaches in the study of prebiotic systems. We consider two such cases here that have been published in the literature: the environmental sensitivity of prebiotic compartmentalisation and the transmission of ultraviolent (UV) light in complex aqueous solutions.

Prebiotic membrane-bound compartments have previously been subjected to a diverse range of environmental analogue conditions - both in the lab, and in the field. An outcome of these studies is that certain simple prebiotically plausible amphiphiles will spontaneously assemble into compartments in freshwater and modern hot spring systems but will not do so in seawater [12]. Meanwhile, other classes of amphiphiles are quite robust to the interferences present in seawater [82]. Much is also known about the response of these structures to $\mathrm{pH}$, ionic strength, and temperature [2,12,82-87], from which a picture is emerging of which compartments may plausibly have been present in end-member prebiotic environments.

Ultra-violet light is a crucial component of several recently proposed reaction schemes, acting to drive otherwise challenging steps in a high yielding and stereoselective manner $[3,6]$. However, many bystander species may attenuate the transmission of UV light in geochemically realistic complex aqueous solutions. Ranjan et al [88] found that Fe-containing species in e.g., ferrocyanide lakes are efficient at attenuating UV transmission, diminishing the potential for UV-driven constructive organic synthesis, but similarly slowing UV-driven degradation of other molecules that may go on to accumulate and constructively interact along different paths, e.g., meteoritic nucleobases [89]. 
The existing body of work on compartment stability and UV light transmission in the presence of varying environmental interferences provides a model for future work on more complex systems. Designing wet chemistry experiments from an interference chemistry perspective is evidently feasible at some level, although the challenge of understanding cause and effect in such experiments will scale with 1) the complexity of the reaction system at hand, 2) the level of detail in which an analogue environment is constructed, and 3) the difficulty of tracking the outcome variable of interest, e.g., energy flow, information transfer, disequilibrium behaviour, and the time-resolved speciation of products. Computer models that tune parameters in search of an optimal outcome may help to circumvent these problems, providing a way to efficiently explore prebiotically plausible parameter space. Standing in the way of such an approach is the fact that many of the parameters needed to obtain meaningful results with any such model, e.g., reaction rate and equilibrium constants, are poorly known. A general shift towards the measurement and collation of fundamental kinetic and thermodynamic data will be needed to properly formulate computational models of interference chemistry. Having initially reproduced wet-chemistry benchmark experiments, interference chemistry models would have great future potential to explore parameter space that is less feasible to test in the lab, e.g., regional-to-global scale environmental processes, on geological timescales (Table 2).

\section{Conclusions}

Systems chemistry aims to explore a synthetic network of particular interacting chemical species using reactants that may have co-occurred on early Earth (Figure 2). This approach can be extended by using interference chemistry to translate between laboratory and geochemical environmental constraints. In contrast, interference chemistry involves taking the pathways produced by systems chemistry research and subjecting them to the effects of environmental stress. In this way, a wider parameter space for otherwise plausible pathways can be explored. By adjusting single reactions as well as systems to identify sensitivity to individual and composite environmental interferences, we can begin to quantify scenario efficacy within that plausible parameter space. Such information will then provide insights on which direction to go next - both in our search for viable prebiotic pathways, and in our search for likely geological environments in the prebiotic era.

An interference chemistry approach opens the door to a two-way flow of information between prebiotic chemistry and the study of early planetary environments: whereby the reactions that drove the origin of life will have acted to shape both local environments and ultimately global planetary conditions [26]. At the same time, prevailing environmental conditions will have determined the plausibility and feasibility of particular origin of life scenarios. Interference chemistry may therefore be leveraged in pursuit of dual constraints on (1) wider environmental conditions at the dawn of life and (2) the efficacy of prebiotic systems taking place in specific environments. By systematising these two flows of information, interreference chemistry offers one possible way to quantify the prebiotic plausibility of scenarios for the origin of life.

It is not only geochemistry that may be utilised in an interference chemistry approach. The same concept naturally extends to origins research in the fields of synthetic biology and exoplanetary science, which should offer other unique regions of parameter space with which to estimate the plausibility of competing origin scenarios. Interference chemistry is well equipped to integrate previous data and new developments in each of these fields into constraints on plausibly prebiotic environmental boundary conditions. Overall, our proposed approach would take full advantage of the vast amount of work that has been carried out across decades of early Earth and origin of life science. All prebiotically plausible reaction systems, both successful and 'failed', would be redefined in our proposed framework as indicative of either constructive or destructive interference chemistry taking place on early Earth. 


\section{Acknowledgements}

C. W. acknowledges NERC and UKRI for support through a NERC DTP studentship, grant number NE/L002507/1. P. B. R. is grateful for funding by the Simons Foundation (SCOL Grant \#599634). Members of he Cambridge Initiative for Planetary Science and Life in the Universe, Dr Oliver Maguire, and Dr Helen Williams are all thanked for their constructively interference in the origin of this paper.

\section{References}

1. Yadav, M.; Kumar, R.; Krishnamurthy, R. Chemistry of Abiotic Nucleotide Synthesis. Chem Rev 2020, 120, 4766-4805, doi:10.1021/acs.chemrev.9b00546.

2. Bonfio, C.; Russell, D.A.; Green, N.J.; Mariani, A.; Sutherland, J.D. Activation Chemistry Drives the Emergence of Functionalised Protocells. Chem Sci 2020, doi:10.1039/d0sc04506c.

3. Patel, B.H.; Percivalle, C.; Ritson, D.J.; Duffy, C.D.; Sutherland, J.D. Common Origins of RNA, Protein and Lipid Precursors in a Cyanosulfidic Protometabolism. Nat Chem 2015, 7, 301-307, doi:10.1038/nchem.2202.

4. Liu, Z.; Wu, L.-F.; Xu, J.; Bonfio, C.; Russell, D.A.; Sutherland, J.D. Harnessing Chemical Energy for the Activation and Joining of Prebiotic Building Blocks. Nat Chem 2020, 12, 1023-1028, doi:10.1038/s41557020-00564-3.

5. Bonfio, C.; Caumes, C.; Duffy, C.D.; Patel, B.H.; Percivalle, C.; Tsanakopoulou, M.; Sutherland, J.D. LengthSelective Synthesis of Acylglycerol-Phosphates through Energy-Dissipative Cycling. J Am Chem Soc 2019, 141, 3934-3939, doi:10.1021/jacs.8b12331.

6. Ritson, D.; Sutherland, J.D. Prebiotic Synthesis of Simple Sugars by Photoredox Systems Chemistry. Nat Chem 2012, 4, 895, doi:10.1038/nchem.1467.

7. Wu, L.-F.; Sutherland, J.D. Provisioning the Origin and Early Evolution of Life. Emerg Top Life Sci 2019, 3, ETLS20190011, doi:10.1042/etls20190011.

8. Barge, L.M.; Doloboff, I.J.; Russell, M.J.; VanderVelde, D.; White, L.M.; Stucky, G.D.; Baum, M.M.; Zeytounian, J.; Kidd, R.; Kanik, I. Pyrophosphate Synthesis in Iron Mineral Films and Membranes Simulating Prebiotic Submarine Hydrothermal Precipitates. Geochim Cosmochim Ac 2014, 128, 1-12,

doi:10.1016/j.gca.2013.12.006.

9. Barge, L.M.; Flores, E.; Baum, M.M.; VanderVelde, D.G.; Russell, M.J. Redox and PH Gradients Drive Amino Acid Synthesis in Iron Oxyhydroxide Mineral Systems. Proc National Acad Sci 2019, 116, 201812098, doi:10.1073/pnas.1812098116.

10. Griffith, E.C.; Vaida, V. In Situ Observation of Peptide Bond Formation at the Water-Air Interface. Proc National Acad Sci 2012, 109, 15697-15701, doi:10.1073/pnas.1210029109.

11. Pasek, M.A. A Role for Phosphorus Redox in Emerging and Modern Biochemistry. Curr Opin Chem Biol 2019, 49, 53-58, doi:10.1016/j.cbpa.2018.09.018.

12. Milshteyn, D.; Damer, B.; Havig, J.; Deamer, D. Amphiphilic Compounds Assemble into Membranous Vesicles in Hydrothermal Hot Spring Water but Not in Seawater. Life 2018, 8, 11, doi:10.3390/life8020011. 
13. Damer, B.; Deamer, D. Coupled Phases and Combinatorial Selection in Fluctuating Hydrothermal Pools: A Scenario to Guide Experimental Approaches to the Origin of Cellular Life. Life 2015, 5, 872-887, doi:10.3390/life5010872.

14. Deamer, D.; Damer, B.; Kompanichenko, V. Hydrothermal Chemistry and the Origin of Cellular Life. Astrobiology 2019, 19, 1523-1537, doi:10.1089/ast.2018.1979.

15. Deamer, D. Membranes and the Origin of Life: A Century of Conjecture. J Mol Evol 2016, 83, 159-168, doi:10.1007/s00239-016-9770-8.

16. Deamer, D.; Oro, J. ROLE OF LIPIDS IN PREBIOTIC STRUCTURES. BioSystems 1980, 12, 167-175.

17. Deamer, D. The Role of Lipid Membranes in Life’s Origin. Life 2017, 7, 5, doi:10.3390/life7010005.

18. Eschenmoser, A. The Search for the Chemistry of Life's Origin. Tetrahedron 2007, 63, 12821-12844, doi:10.1016/j.tet.2007.10.012.

19. E., O.L. Prebiotic Chemistry and the Origin of the RNA World. Crit Rev Biochem Mol 2010, 39, 99-123, doi:10.1080/10409230490460765.

20. Haldane, J.B.S. The Origins of Prebiological Systems and of Their Molecular Matrices. Part Perspectives 1965, 11-18, doi:10.1016/b978-1-4832-2861-7.50011-9.

21. Benner, S.A.; Bell, E.A.; Biondi, E.; Brasser, R.; Carell, T.; Kim, H.; Mojzsis, S.J.; Omran, A.; Pasek, M.A.; Trail, D. When Did Life Likely Emerge on Earth in an RNA-First Process? Chemsystemschem 2020, 2, doi:10.1002/syst.201900035.

22. Benner, S.A.; Kim, H.-J.; Biondi, E. Prebiotic Chemistry That Could Not Not Have Happened. Life 2019, 9, 84, doi:10.3390/life9040084.

23. Benner, S.A. Prebiotic Plausibility and Networks of Paradox-Resolving Independent Models. Nat Commun 2018, 9, 5173, doi:10.1038/s41467-018-07274-y.

24. Ruiz-Mirazo, K.; Briones, C.; Escosura, A. de la Prebiotic Systems Chemistry: New Perspectives for the Origins of Life. Chem Rev 2014, 114, 285-366, doi:10.1021/cr2004844.

25. Islam, S.; Powner, M.W. Prebiotic Systems Chemistry: Complexity Overcoming Clutter. Chem 2017, 2 , 470-501, doi:10.1016/j.chempr.2017.03.001.

26. Sasselov, D.D.; Grotzinger, J.P.; Sutherland, J.D. The Origin of Life as a Planetary Phenomenon. Sci $A d v$ 2020, 6, eaax3419, doi:10.1126/sciadv.aax3419.

27. Shapiro, R. Prebiotic Ribose Synthesis: A Critical Analysis. Origins Life Evol B 1988, 18, 71-85, doi:10.1007/bf01808782.

28. Shapiro, R. The Improbability of Prebiotic Nucleic Acid Synthesis. Orig Life 1984, 14, 565-570, doi:10.1007/bf00933705.

29. Sutherland, J.D. The Origin of Life-Out of the Blue. Angewandte Chemie Int Ed 2015, 55, 104-121, doi:10.1002/anie.201506585. 
30. Planavsky, N.J.; McGoldrick, P.; Scott, C.T.; Li, C.; Reinhard, C.T.; Kelly, A.E.; Chu, X.; Bekker, A.; Love, G.D.; Lyons, T.W. Widespread Iron-Rich Conditions in the Mid-Proterozoic Ocean. Nature 2011, 477, 448, doi:10.1038/nature10327.

31. Scott, C.; Planavsky, N.J.; Dupont, C.L.; Kendall, B.; Gill, B.C.; Robbins, L.J.; Husband, K.F.; Arnold, G.L.; Wing, B.A.; Poulton, S.W.; et al. Bioavailability of Zinc in Marine Systems through Time. Nat Geosci 2013, 6, 125, doi:10.1038/ngeo1679.

32. Partin, C.A.; Bekker, A.; Planavsky, N.J.; Scott, C.T.; Gill, B.C.; Li, C.; Podkovyrov, V.; Maslov, A.; Konhauser, K.O.; Lalonde, S.V.; et al. Large-Scale Fluctuations in Precambrian Atmospheric and Oceanic Oxygen Levels from the Record of U in Shales. Earth Planet Sc Lett 2013, 369, 284-293, doi:10.1016/j.epsl.2013.03.031.

33. Planavsky, N.J.; Asael, D.; Hofmann, A.; Reinhard, C.T.; Lalonde, S.V.; Knudsen, A.; Wang, X.; Ossa, F.O.; Pecoits, E.; Smith, A.J.B.; et al. Evidence for Oxygenic Photosynthesis Half a Billion Years before the Great Oxidation Event. Nat Geosci 2014, 7, 283, doi:10.1038/ngeo2122.

34. Lyons, T.W.; Reinhard, C.T.; Planavsky, N.J. The Rise of Oxygen in Earth's Early Ocean and Atmosphere. Nature 2014, 506, 307, doi:10.1038/nature13068.

35. Ge, R.; Wilde, S.A.; Nemchin, A.A.; Whitehouse, M.J.; Bellucci, J.J.; Erickson, T.M.; Frew, A.; Thern, E.R. A 4463 Ma Apparent Zircon Age from the Jack Hills (Western Australia) Resulting from Ancient $\mathrm{Pb}$ Mobilization. Geology, doi:10.1130/g39894.1.

36. Valley, J.W.; Peck, W.H.; King, E.M.; Wilde, S.A. A Cool Early Earth. Geology 2002, 30, 351-354, doi:10.1130/0091-7613(2002)030<0351:acee>2.0.co;2.

37. Zahnle, K.; Arndt, N.; Cockell, C.; Halliday, A.; Nisbet, E.; Selsis, F.; Sleep, N.H. Emergence of a Habitable Planet. Space Sci Rev 2007, 129, 35-78, doi:10.1007/s11214-007-9225-z.

38. Shaw, G.H. Earth's Atmosphere - Hadean to Early Proterozoic. Chemie Der Erde - Geochem 2008, 68, 235264, doi:10.1016/j.chemer.2008.05.001.

39. Sessions, A.L.; Doughty, D.M.; Welander, P.V.; Summons, R.E.; Newman, D.K. The Continuing Puzzle of the Great Oxidation Event. Curr Biol 2009, 19, R567-R574, doi:10.1016/j.cub.2009.05.054.

40. Harrison, T.M. The Hadean Crust: Evidence from >4 Ga Zircons. Annu Rev Earth Pl Sc 2009, 37, 479-505, doi:10.1146/annurev.earth.031208.100151.

41. Barley, M.E.; Bekker, A.; Krapež, B. Late Archean to Early Paleoproterozoic Global Tectonics, Environmental Change and the Rise of Atmospheric Oxygen. Earth Planet Sc Lett 2005, 238, 156-171, doi:10.1016/j.epsl.2005.06.062.

42. Rollinson, H. When Did Plate Tectonics Begin? Geology Today 2007, 23, 186-191, doi:10.1111/j.13652451.2007.00631.x.

43. Sleep, N.H. The Hadean-Archaean Environment. Csh Perspect Biol 2010, 2, a002527, doi:10.1101/cshperspect.a002527.

44. Bell, E.A.; Harrison, T.M.; McCulloch, M.T.; Young, E.D. Early Archean Crustal Evolution of the Jack Hills Zircon Source Terrane Inferred from $\mathrm{Lu}-\mathrm{Hf}, 207 \mathrm{~Pb} / 206 \mathrm{~Pb}$, and $\Delta 180$ Systematics of Jack Hills Zircons. Geochim Cosmochim Ac 2011, 75, 4816-4829, doi:10.1016/j.gca.2011.06.007. 
45. Roberts, N.M.W.; Spencer, C.J. The Zircon Archive of Continent Formation through Time. Geological Soc Lond Special Publ 2014, 389, SP389.14, doi:10.1144/sp389.14.

46. Marchi, S.; Bottke, W.F.; Elkins-Tanton, L.T.; Bierhaus, M.; Wuennemann, K.; Morbidelli, A.; Kring, D.A. Widespread Mixing and Burial of Earth's Hadean Crust by Asteroid Impacts. Nature 2014, 511, 578, doi:10.1038/nature13539.

47. Thomassot, E.; O’Neil, J.; Francis, D.; Cartigny, P.; Wing, B.A. Atmospheric Record in the Hadean Eon from Multiple Sulfur Isotope Measurements in Nuvvuagittuq Greenstone Belt (Nunavik, Quebec). Proc National Acad Sci 2015, 112, 707-712, doi:10.1073/pnas.1419681112.

48. Hastie, A.R.; Fitton, J.G.; Bromiley, G.D.; Butler, I.B.; Odling, N.W.A. The Origin of Earth's First Continents and the Onset of Plate Tectonics. Geology 2016, 44, 855-858, doi:10.1130/g38226.1.

49. Smit, M.A.; Mezger, K. Earth's Early 02 Cycle Suppressed by Primitive Continents. Nat Geosci 2017, 10, 788, doi:10.1038/ngeo3030.

50. Johnson, T.E.; Brown, M.; Gardiner, N.J.; Kirkland, C.L.; Smithies, R.H. Earth's First Stable Continents Did Not Form by Subduction. Nature 2017, 543, 239, doi:10.1038/nature21383.

51. O'Neill, C.; Turner, S.; Rushmer, T. The Inception of Plate Tectonics: A Record of Failure. Philosophical Transactions Royal Soc 2018, 376, 20170414, doi:10.1098/rsta.2017.0414.

52. Toner, J.D.; Catling, D.C. A Carbonate-Rich Lake Solution to the Phosphate Problem of the Origin of Life. Proc National Acad Sci 2020, 117, 883-888, doi:10.1073/pnas.1916109117.

53. Toner, J.D.; Catling, D.C. Alkaline Lake Settings for Concentrated Prebiotic Cyanide and the Origin of Life. Geochim Cosmochim Ac 2019, 260, 124-132, doi:10.1016/j.gca.2019.06.031.

54. Visscher, P.T.; Gallagher, K.L.; Bouton, A.; Farias, M.E.; Kurth, D.; Sancho-Tomás, M.; Philippot, P.; Somogyi, A.; Medjoubi, K.; Vennin, E.; et al. Modern Arsenotrophic Microbial Mats Provide an Analogue for Life in the Anoxic Archean. Commun Earth Environ 2020, 1, 24, doi:10.1038/s43247-020-00025-2.

55. McCleskey, B.; Ball, J.W.; Nordstrom, D.K.; Holloway, J.M.; Taylor, H.E. Water-Chemistry Data for Selected Hot Springs, Geysers, and Streams in Yellowstone National Park, Wyoming, 2001-2002. Open-File Report 2004-1316 2005.

56. Lyons, W.B.; Mikucki, J.A.; German, L.A.; Welch, K.A.; Welch, S.A.; Gardner, C.B.; Tulaczyk, S.M.; Pettit, E.C.; Kowalski, J.; Dachwald, B. The Geochemistry of Englacial Brine From Taylor Glacier, Antarctica. J Geophys Res Biogeosciences 2019, 124, 633-648, doi:10.1029/2018jg004411.

57. Hodgkinson, M.R.S.; Webber, A.P.; Roberts, S.; Mills, R.A.; Connelly, D.P.; Murton, B.J. Talc-Dominated Seafloor Deposits Reveal a New Class of Hydrothermal System. Nat Commun 2015, 6, 10150, doi:10.1038/ncomms10150.

58. Hao, J.; Sverjensky, D.A.; Hazen, R.M. A Model for Late Archean Chemical Weathering and World Average River Water. Earth Planet Sc Lett 2017, 457, doi:10.1016/j.epsl.2016.10.021.

59. Morse, J.W.; Mackenzie, Fred.F. Hadean Ocean Carbonate Chemistry. Aquatic Geochemistry 1998.

60. Mulkidjanian, A.Y.; Bychkov, A.Yu.; Dibrova, D.V.; Galperin, M.Y.; Koonin, E.V. Origin of First Cells at Terrestrial, Anoxic Geothermal Fields. Proc National Acad Sci 2012, 109, E821-E830,

doi:10.1073/pnas.1117774109. 
61. Edmonds Particle Geochemistry in the Rainbow Hydrothermal Plume, Mid-Atlantic Ridge.

62. Rasmussen, B.; Muhling, J.R.; Suvorova, A.; Fischer, W.W. Apatite Nanoparticles in 3.46-2.46 Ga Iron Formations: Evidence for Phosphorus-Rich Hydrothermal Plumes on Early Earth. Geology 2021, doi:10.1130/g48374.1.

63. Crowe, S.A.; Paris, G.; Katsev, S.; Jones, C.; Kim, S.-T.; Zerkle, A.L.; Nomosatryo, S.; Fowle, D.A.; Adkins, J.F.; Sessions, A.L.; et al. Sulfate Was a Trace Constituent of Archean Seawater. Science 2014, 346, 735-739, doi:10.1126/science.1258966.

64. Ranjan, S.; Todd, Z.R.; Sutherland, J.D.; Sasselov, D.D. Sulfidic Anion Concentrations on Early Earth for Surficial Origins-of-Life Chemistry. Astrobiology 2018, 18, 1023-1040, doi:10.1089/ast.2017.1770.

65. Seyfried, W.E.; Pester, N.J.; Tutolo, B.M.; Ding, K. The Lost City Hydrothermal System: Constraints Imposed by Vent Fluid Chemistry and Reaction Path Models on Subseafloor Heat and Mass Transfer Processes. Geochim Cosmochim Ac 2015, 163, 59-79, doi:10.1016/j.gca.2015.04.040.

66. Dellinger, M.; Gaillardet, J.; Bouchez, J.; Calmels, D.; Galy, V.; Hilton, R.G.; Louvat, P.; France-Lanord, C. Lithium Isotopes in Large Rivers Reveal the Cannibalistic Nature of Modern Continental Weathering and Erosion. Earth Planet Sc Lett 2014, 401, 359-372, doi:10.1016/j.epsl.2014.05.061.

67. Lang, S.Q.; Früh-Green, G.L.; Bernasconi, S.M.; Brazelton, W.J.; Schrenk, M.O.; McGonigle, J.M. DeeplySourced Formate Fuels Sulfate Reducers but Not Methanogens at Lost City Hydrothermal Field. Sci Rep-uk 2018, 8, 755, doi:10.1038/s41598-017-19002-5.

68. Negrel, P.; Petelet-Giraud, E.; Kloppmann, W.; Casanova, J. Boron Isotope Signatures in the Coastal Groundwaters of French Guiana. Water Resour Res 2002, 38, 44-1-44-5, doi:10.1029/2002wr001299.

69. Uppström, L.R. The Boron/Chlorinity Ratio of Deep-Sea Water from the Pacific Ocean. Deep Sea Res Oceanogr Abstr 1974, 21, 161-162, doi:10.1016/0011-7471(74)90074-6.

70. Jones, C.; Nomosatryo, S.; Crowe, S.A.; Bjerrum, C.J.; Canfield, D.E. Iron Oxides, Divalent Cations, Silica, and the Early Earth Phosphorus Crisis. Geology 2015, 43, 135-138, doi:10.1130/g36044.1.

71. Berndt, M.E.; Seyfried, W.E. Boron, Bromine, and Other Trace Elements as Clues to the Fate of Chlorine in Mid-Ocean Ridge Vent Fluids. Geochim Cosmochim Ac 1990, 54, 2235-2245, doi:10.1016/00167037(90)90048-p.

72. Neal, C.; Neal, M.; Hughes, S.; Wickham, H.; Hill, L.; Harman, S. Bromine and Bromide in Rainfall, Cloud, Stream and Groundwater in the Plynlimon Area of Mid-Wales. Hydrol Earth Syst Sc 2007, 11, 301-312, doi:10.5194/hess-11-301-2007.

73. Hurwitz, S.; Clor, L.E.; McCleskey, R.B.; Nordstrom, D.K.; Hunt, A.G.; Evans, W.C. Dissolved Gases in Hydrothermal (Phreatic) and Geyser Eruptions at Yellowstone National Park, USA. Geology 2016, 44, 235238, doi:10.1130/g37478.1.

74. Bradley, A.S.; Hayes, J.M.; Summons, R.E. Extraordinary 13C Enrichment of Diether Lipids at the Lost City Hydrothermal Field Indicates a Carbon-Limited Ecosystem. Geochim Cosmochim Ac 2009, 73, 102-118, doi:10.1016/j.gca.2008.10.005.

75. Zheng, X.-Y.; Beard, B.L.; Reddy, T.R.; Roden, E.E.; Johnson, C.M. Abiologic Silicon Isotope Fractionation between Aqueous Si and Fe(III)-Si Gel in Simulated Archean Seawater: Implications for Si Isotope Records in 
Precambrian Sedimentary Rocks. Geochim Cosmochim Ac 2016, 187, 102-122, doi:10.1016/j.gca.2016.05.012.

76. Seyfried, W.E.; Pester, N.J.; Ding, K.; Rough, M. Vent Fluid Chemistry of the Rainbow Hydrothermal System (36 N, MAR): Phase Equilibria and in Situ PH Controls on Subseafloor Alteration Processes. Geochim Cosmochim Ac 2011, 75, 1574-1593, doi:10.1016/j.gca.2011.01.001.

77. Douville, E.; Charlou, J.L.; Oelkers, E.H.; Bienvenu, P.; Colon, C.F.J.; Donval, J.P.; Fouquet, Y.; Prieur, D.; Appriou, P. The Rainbow Vent Fluids $\left(36^{\circ} 14^{\prime} \mathrm{N}, \mathrm{MAR}\right)$ : The Influence of Ultramafic Rocks and Phase Separation on Trace Metal Content in Mid-Atlantic Ridge Hydrothermal Fluids. Chem Geol 2002, 184, 37-48, doi:10.1016/s0009-2541(01)00351-5.

78. Kelley, D.S.; Karson, J.A.; Blackman, D.K.; Früh-Green, G.L.; Butterfield, D.A.; Lilley, M.D.; Olson, E.J.; Schrenk, M.O.; Roe, K.K.; Lebon, G.T.; et al. An Off-Axis Hydrothermal Vent Field near the Mid-Atlantic Ridge at $30^{\circ}$ N. Nature 2001, 412, 145-149, doi:10.1038/35084000.

79. Charlou, J.L.; Donval, J.P.; Fouquet, Y.; Jean-Baptiste, P.; Holm, N. Geochemistry of High H2 and CH4 Vent Fluids Issuing from Ultramafic Rocks at the Rainbow Hydrothermal Field ( $\left.36^{\circ} 14^{\prime} \mathrm{N}, \mathrm{MAR}\right)$. Chem Geol 2002, 191, 345-359, doi:10.1016/s0009-2541(02)00134-1.

80. Krissansen-Totton, J.; Arney, G.N.; Catling, D.C. Constraining the Climate and Ocean PH of the Early Earth with a Geological Carbon Cycle Model. Proc National Acad Sci 2018, 115, 201721296, doi:10.1073/pnas.1721296115.

81. Kadoya, S.; Krissansen-Totton, J.; Catling, D.C. Probable Cold and Alkaline Surface Environment of the Hadean Earth Caused by Impact Ejecta Weathering. Geochem Geophys Geosystems 2020, 21, doi:10.1029/2019gc008734.

82. Jordan, S.F.; Rammu, H.; Zheludev, I.N.; Hartley, A.M.; Maréchal, A.; Lane, N. Promotion of Protocell SelfAssembly from Mixed Amphiphiles at the Origin of Life. Nat Ecol Evol 2019, 3, 1705-1714, doi:10.1038/s41559-019-1015-y.

83. Yanagawa, H.; Ogawa, Y.; Kojima, K.; Ito, M. Construction of Protocellular Structures under Simulated Primitive Earth Conditions. Origins Life Evol B 1988, 18, 179-207, doi:10.1007/bf01804670.

84. Terasawa, H.; Nishimura, K.; Suzuki, H.; Matsuura, T.; Yomo, T. Coupling of the Fusion and Budding of Giant Phospholipid Vesicles Containing Macromolecules. Proc National Acad Sci 2012, 109, 5942-5947, doi:10.1073/pnas.1120327109.

85. Joshi, M.P.; Samanta, A.; Tripathy, G.R.; Rajamani, S. Formation and Stability of Prebiotically Relevant Vesicular Systems in Terrestrial Geothermal Environments. Life 2017, 7, 51, doi:10.3390/life7040051.

86. Lopez, A.; Fiore, M. Investigating Prebiotic Protocells for A Comprehensive Understanding of the Origins of Life: A Prebiotic Systems Chemistry Perspective. Life 2019, 9, 49, doi:10.3390/life9020049.

87. Jordan, S.F.; Nee, E.; Lane, N. Isoprenoids Enhance the Stability of Fatty Acid Membranes at the Emergence of Life Potentially Leading to an Early Lipid Divide. Interface Focus 2019, 9, 20190067, doi:10.1098/rsfs.2019.0067.

88. Ranjan, S.; Kufner, C.L.; Lozano, G.G.; Todd, Z.R.; Haseki, A.; Sasselov, D.D. UV Transmission in Natural Waters on Prebiotic Earth. Arxiv 2021. 
89. Pearce, B.K.D.; Pudritz, R.E.; Semenov, D.A.; Henning, T.K. Origin of the RNA World: The Fate of Nucleobases in Warm Little Ponds. 2017, doi:10.1073/pnas.1710339114. 